\title{
Relation to Intervention Unclassifiable
}

National Cancer Institute

\section{Source}

National Cancer Institute. Relation to Intervention Unclassifiable. NCI Thesaurus. Code C68619.

A characteristic used to qualify the adverse event as unclassifiable in term of its relation to the medical intervention. According to WHO causality assessment criteria of suspected adverse reactions it is applicable to an adverse reaction which cannot be judged because information about it is insufficient or contradictory, and cannot be supplemented or verified. 